\title{
DISCRIMINANT FUNCTION ANALYSIS OF REGIONAL ECONOMIC DEVELOPMENT
}

\author{
Warren F. Mazek and Charles T. Haworth
}

Florida State University*

This paper examines the usefulness of discriminant analysis in as sessing regional economic development. Discriminant analysis is a multivariate statistical technique which may be used to isolate those variables most closely associated with regional development. These variables form a discriminant function which gauges the relative importance of the variables to the process of regional development. In addition, the discriminant function can be used to classify the development level of each region. The resulting classification and the discriminant function can be useful policy instruments for national or state agencies charged with furthering regional economic development.

We follow closely the approach used by Irma Adelman and Cynthia Morris in their analysis of underdeveloped nations. ${ }^{1}$ They used discriminant analysis to determine the importance of various factors in the economic growth of underdeveloped nations, as well as to classify such nations by development potential. Later we will refer to their work on underdeveloped nations; for the present it is instructive to consider their explanation of the methodology inherent in discriminant analysis. Adelman and Morris state that the re are two basic empirical approaches to identifying the factors critical to the development process and to identifying development potential. The one approach is more theoretical. ${ }^{2}$ It begins with a theoretical model of how areas develop and then estimates the parameters of that model, statistically. The statis tical estimates are used to determine the importance of each variable and of a nation's development potential.

The other approach is more empirical. Discriminant analysis is of this type. The analysis begins with the data and determines the variables critical to development through statistical analysis. Primarily, the variables selected are operational, i.e., designed to predict development. Theory enters in only in an ad hoc fashion. Each variable is a measure of a performance characteristic which seems to have some causal bearing upon development. ${ }^{3}$

In order to determine the usefulness of discriminant analysis in assessing regional economic development, we have applied the technique to Florida counties in the 1960's. Florida is an especially good laboratory for this experiment because of the (generally unappreciated) diversity of its income base--tourism, retirement, agriculture, and industry.

\section{The Procedure}

Since this is the first application of this form of statistical analysis to regional problems, the procedure is described in some detail. ${ }^{4}$ Like multiple regression, discriminant analysis estimates an equation which has the "best fit." While multiple regression explains the level of a single variable, the "best fit" in discriminant analysis is the extent to which groupings are explained by the discriminant function. In this study, the sixty-seven Florida counties were classified by level of development into three groups--High, Middle, and Low. The estimated discriminant function is that linear combination of variables which best differentiates among these three developmental groups. In short, discriminant analysis explains group membership. 
Substitution of a given county's measurements on the set of variables into the discriminant function yields that county's discriminant score. This score maybe interpreted as an index of development. The set of scores for the set of Florida counties is useful in assessing regional development. As will be demonstrated later, the analysis also generates probabilities which can be helpful in classifying counties for development analysis.

The approachwe used for this study was a stepwise procedure resembling stepwise multiple regression. Specifically, variables were added to the discriminant function until there was no significant increase in the among groups sum of squares relative to the within groups sum of squares. In other words, separation among groups in terms of their performance on the set of selected variables is maximized.

\section{The Groupings}

In the first stage, the 67 Florida counties were grouped by three levels of development--High, Middle, and Low. The groupings used in discriminant analysis are judgmental, to a large extent. Thus, the groupings used in this study reflect our view that regional economic development is multidimensional and ought to be measured by more than per capita income alone. Poverty and unemployment are also important dimensions of regional economic "health." Accordingly, the following decision rule was followed in constructing the groupings: (1) eounties were arrayed by per capita income, (2) sizeable gaps in per capita income were used to establish the cut-off points among the groups, (3) counties in the highest per capita income group with a poverty level below average and/or unemployment in the lowest quartile were removed and left unclassified in the initial analysis. ${ }^{5}$ Thus, those counties left in the High Development Group had high per capita income and satisfactory unemployment and poverty performance. (4) Counties in the middle group with unemployment and poverty in the lowest quartile were also excluded from the initial analysis. In total, five counties were excluded. They were later classified on the basis of the probabilities derived from the discriminant analysis. The complete listing of groups is found in Table I.

The use of groupings based upon several indicators is one of the highly attractive features of discriminant analysis. If multiple regression analysis of regional development were undertaken, only a single measure of regional development--probably per capita income--could be used. Because discriminant analysis deals with orderings (groupings), information is lost: while per capita income indicates the size of the difference between any two counties, groupings do not. Nevertheless, there is some advantage to discriminant analysis because it does permit the multidimensional viewpoint.

\section{Variables}

A complete listing and description of the seventeen variables used in the analysis is in the Appendix. ${ }^{6}$ The variables are primarily economic, although some demographic variables are included. This is in contrast to the Adelman-Morris studywhich utilized a larger number of social and political indicators as well as economic variables. Our exclusion of social and political variables was based upon the presumption that there is much more homogeneity among counties on social and political variables than there is among nations. This presumption may require further investigation.

There are two main criteria used in selecting variables: causality and the nature of simultaneity in the relationships among variables. The causality criterion was the extent to which a given variable measured a regional char- 
acteristic which might affect the level of regional development--per capita income, poverty, and unemployment. As is evident from the list of included variables, we have tried to gauge the impact of employment structure, of tourism, of retirement, etc., upon the level of development. The variable, income in contiguous counties (per capita) was designed to capture the effect of job commuting upon residential patterns of income. However, since Florida counties are large, there was reason to believe that this variable would not be important for the set of Florida counties, although it might be highly important in several instances.

The loan-to-deposit ratio was included with some question as to how to interpret the results should it appear in the discriminant function. The money and banking literature views the loan-to-deposit ratio as reflecting two conflicting possibilities: a low loan-to-deposit ratio might mean a lack of investment opportunities, orit might mean that unduly conservative banking practices are being followed. While our study provides no evidence as to the relative importance of these two potential hypotheses, it was decided to retain the variable to see if it had any operational significance in explaining levels of regional development.

The other criterion for selecting variables was the extent of simultaneity between the given variable and the level of development. If the given variable seemed to be exogeneous of the level of development, the variable was used in the discriminant analysis. The index of natural amenities is such a variable. Variables mutually interdependent with the level of development involved other considerations, especially because discriminant analysis is a single equation, multivariate technique. This form of simultaneity is nota serious disadvantage if the sole purpose is prediction. But if explanation is the goal, the simultaneity is a problem.

Ourapproach compromises the prediction and explanation goals. Obvious simultaneity is ruled out, as in those instances where the given variable is simply another indicator of regional development. In other cases, the situation is not so clear: the given variable may be a causal determinant of regional development or it may be determined largely by the level of regional development. In instances where the expected direction of causality is unclear, the variable was retained for analysis. The educational level of the population is a variable of this type. The educational level of the population might have incuded regional development or it might have been the cons equence of development as the highly educated move into developing a reas.

\section{The Discriminant Functions}

The application of discriminant functions to the analys is of the development level of Florida counties appears to have been successful, statistically. Like the Adelman-Morris study of underdeveloped countries, our discriminant function explains 97 percent of the discriminable variance between groups. It is interesting that our results were achieved with economic variables, while their variables were social, political, and economic. The stepwise procedure resulted in five variables being selected from the initial list of seventeen. These are: transfer components $(\mathrm{T})$, the labor force participation rate $(\mathrm{L})$, the education level $(\mathrm{E})$, the loan-to-deposit ratio (D), and the index of natural amenities (A). The discriminant function is: ${ }^{7}$

$\mathrm{D}_{1}=-1.77-1.70 \mathrm{~T}+1.20 \mathrm{E}+.05 \mathrm{D}+.89 \mathrm{~L}+.90 \mathrm{~A}$

As expected, a priori, the labor force participation rate (L) is pos- 
itively related to the level of regional development. For one thing, it has beenwell established that unavailability of jobs tends to lower the labor force participation rate via the discouragement factor. Second, high participation rates might reflect employment of the secondary labor force, thereby tending to reduce poverty and raise incomes, per capita. The positive sign of the coefficient of the educational level $(E)$ is also as expected. As mentioned earlier, the analysis does not indicate whether education is growth-induced or growth-inducing. We only know that the variable is useful in predicting development. Its appearance in the function emphasizes the necessity of additional study of the development-education nexus.

The loan-to-deposit ratio (D) enters with the expected positive sign. Since this could be the result of conservative banking policies or the lack of investmentopportunities, additional study of the relationship of the loan-todeposit ratio with regional development is warranted.

The analysis shows that the natural amenities (A) are an important discriminator of regional development within Florida. Tourism and retirement are important. Several factors may be at work here. For one, while employment in the tourist industry tends to be in low wage service industries, proprietary income is usually large. Second, much of Florida, including the tourist centers, is still fairly rural and still engaged in de-agriculturization. Jobs in low wage tourist industries might pay more than jobs in agriculture, the reby raising per capita income as tourism grows and agriculture declines. Third, poverty is above the national average in most Florida counties so that a couple living on a small retirement pension might have more income, per capita, than much of the rest of the population. This last element is especially significant because of the fact that most counties in Florida have poverty substantially in excess of the national average.

The coefficient of the last variable of our function (T) shows that the larger are transfer payments, the lower is the level of development. Transfer payments are government transfer payments consisting of social security and medicare payments, state unemployment insurance, railroad retirement and unemployment insurance, government retirement programs, veterans' benefits and direct relief. Veterans' benefits, especially military retirement, are an especially large component. Since welfare payments a re a part of the transfer components variable, we investigated the possibility that their inclusion was responsible for the appearance of the variable in the discriminant function. However, retirement income comprises 80 percent of transfer income, with welfare payments constituting about 15 percent. ${ }^{8}$ The minor importance of welfare payments is perhaps not surprising since, for the period covered by the study, the maximum welfare payment was $\$ 85$ for a mother with four or more dependent children.

To further examine the transfer components variable another discriminant function, $D_{2}$, was run. In this analysis, classification and grouping were done on the basis of income per worker, rather than per capita income. In this manner, transfer payments were deleted from the income measure used to delineate groups. Income per worker is simply income earned in production divided by the number employed. The resulting discriminant function is:

$$
D_{2}=-1.09-2.75 \mathrm{~T}-1.38 \mathrm{~L}-.33 \mathrm{~N}
$$

$\mathrm{N}$ is the percentage of employment in nonagricultural activities. The transfer component (T) still persists, as does the labor force participation rate (L). The development level, based primarily upon income per worker, is 
inversely related to the percentage of income which is transfer income. This suggests the following interpretation: retirement income, when spent, tends to lower income earned in production per worker. Perhaps these expenditures are for services which tend to pay low wages.

The first discriminant function, $D_{1}$, suggests a communality between three of the variables included in it--the labor force participation rate, the index of natural amenities, and the loan-to-deposit ratio. The possible communality is job opportunity. The positive sign of the labor force participation rate is consistent with the job availability thesis. Whether the positive sign of the loan-to-deposit ratio signifies banking conservatism or the lack of investment opportunity, both factors imply a lower level of jobs than there might otherwise be. Similarly, we observed that the index of natural amenities might indicate that the availability of jobs in tourism raises per capita incomes as agricultural employment declines. In short, there are some indications that growth in employment opportunity in compa ratively rural Florida cando much to raise per capita incomes. Welfare as seen by the economist and as seen by the local Chamber of Commerce might not be so far apart after all.

Variables included in the function could indicate a broad range of socioeconomic processes. Accordingly, it is instructive to examine the simple correlations of the variables included in the function $\left(D_{1}\right)$ with the excluded variables (see Table II). The percentage of the population over 65 years of age is the variable most strongly correlated with the transfer component variable, with the education level, and also with the index of natural amenities. Once again the importance of retirement in analyzing development levels within Florida is apparent. In the cases of the labor force participation rate and the loan-to-deposit ratio, the variable most highly correlated with each is the education level, which is already included in the discriminant function. In short, statistical differences between the variables included in the discriminant function and those excluded are not small. The included variables do not appear to be operating as proxy variables for the excluded variables. This is in contrast to the Adelman-Morris study where the included and excluded variables were highly collinear, making it difficult to say that the included variables were the critical ones.

The labor force participation rate, education level, amenities, and transfer payment variables discriminate about equally well between the medium and high groups as well as between the medium and low groups. This is evidenced in Table III which gives the means of the variables by group. The means of the loan-to-deposit ratio are revealing, though. The mean loan-to-deposit ratio by group is not correlated with the level of development. Moreover, the variable discriminates very well between the middle and low groups and hardly at all between the high and middle groups. This nicely illustrates the advantage of a multivariate approach: relationships are disclosed which are not apparent from a univariate analysis of correlation.

The quality of a given discriminant function depends upon at least three factors: the reasonableness of the variables included, the percentage of the discriminable variance accounted for (comparable to $\mathrm{R}^{2}$ in multiple regression), and the extent to which there is separation among the groups. Separation, in this context, is the distance between the means of the discriminant scores by group. On thiscriterion, $D_{1}$ is fairly satisfactory. The mean discriminant score of the high group is 1.90 , of the middle group is -.96, and of the low group is -4.63 . In terms of discriminant scores, 25 percent of the counties in the middle group overlap the high group; 16 percent of the high group overlap the middle group, 6 percent of the middle 
overlap the low group, and 10 percent of the low overlap the middle group. These overlap figures are nearly identical to those obtained by AdelmanMorris.

The discriminant function, D1, selected five variables most highly related to the level of regional development. By normalizing $D_{1}$, the coefficients of the normalized function indicate the relative importance of the variables. This normalized function is:

$$
D_{1}^{\prime}=-86.7-73.2 T+59.8 E+48.2 L+49.7 A
$$

The transfer component ( $T$ ) is most important, followed by the education level $(\mathrm{E})$, the index of natural amenities (A), the labor force participation rate (L), and the loan-to-deposit ratio (D).

\section{The Discriminant $\underline{\text { Scores }}$ and Probabilities}

The discriminant analysis provides scores and probabilities which make it possible to analyze the classification of each county. The discriminant scores arearrived at by substituting the given county's measurement on each of the five variables into the discriminant function, $D_{1}$. These scores or indices of the level of regional development are found in Table IV.

At the same time, the discriminant analysis calculated probabilities for each county which are useful in assessing each county's development situation. The initial classification into high, middle, and low development levels was made, as explained earlier, on the basis of per capita income, poverty, and unemployment. The probabilities lead to a reclassification based, instead, upon the variables in the discriminant function--education, labor force participation rate, etc. Using the measurements of a given county on the set of variables in the discriminant function, $D_{1}$, and the set of measurements of all of the counties in a development group, the probability that the given county belongs to the given development group is calculated. Thus the probabilities indicate that in the originally classified high group, Highland, Lake, and Pinellas more nearly resemble the middle group in terms of performance characteristics (see Table IV). Similarly, Alachua, Bay, Broward, and St. John's in the middle group more nearly resemble the high group. The probabilities also indicate that in the originally classified low group, Okeechobee, Seminole, and Suwannee counties are closer to the middle group's development characteristics.

These discrepancies between the original classification and probabilities calculated in the discriminant analysis might indicate at least one of several possibilities. First, the data used to construct the original classification might be in error. Those familiar with regional data estimates will appreciate the seriousness of this possibility. Second, the discrepancies might mean that the process by which regional development occurs is only the same for most counties. In other counties, the development process might be quite different and the discriminant analysis had not identified the se underlying processes. Whatever the reason, the appearance of these discrepancies suggests additional study of the counties involved.

In addition to assessing previously assigned counties, the discriminant analysis is operationally useful in assigning originally unclassified counties. We have used $D_{1}$ to assign the five counties that were initially unclassified (Table I). Since the mechanics are described elsewhere, we only present the discriminant scores and probabilities for these five counties in Table IV. 9 The probabilities indicate that Dade, Gulf, and Polk are similar to the counties in the high group, Flagler is similar to the middle group, and Charlotte is much like the members of the low group. 
The discriminant analysis could be used to predict potential development. With the discriminant function, $D_{1}$, and the most recent information on the variables in the function, a new set of discriminant scores can be calculated for the set of counties. From these, the counties can be classified as to their potential development over the next few years, assuming that the relationship between development and the performance characteristics will remain stable. We have not made any such predictions or tests thereof, and indeed, know of no such application of discriminant functions to economic analysis. However, this extension of the discriminant method seems promising.

The discriminant analysis could be stopped at this point. However, we continued the analysis so as to achieve as much separation as possible among groups. Specifically the analysis was continued until there were no misclas sifications, thereby reducing the overlap between discriminant scores. In contrast, $D_{1}$ was derived by maximizing the percentage of the variance explained. The analysis began with the reclassification of the 67 counties based upon the probabilities derived from $D_{1}$. A second discriminant function was calculated which was based upon this grouping. The counties misclassified according to this second function were then reclassified. Another discriminant analysis was done and the process repeated several times until there were no misclassifications. This final discriminant function is, in normalized form:

$$
D_{3}=-242.8-114.2 T+227.7 \mathrm{E}+72.4 \mathrm{D}+115.8 \mathrm{~L}-71.2 \mathrm{G}
$$

As in $D_{1}$ transfers $(T)$, education $(E)$, and the loan-to-deposit ratio (D), are included. However, the index of natural amenities (A) is replaced by the percentage over $65(G)$. As noted earlier, this variable is highly correlated with the index of naturalamenities. Again, transfers and education a re most important, in that order. The labor force participation rate rises to third in importance, however. We are encouraged by the fact that the processes described by $D_{2}$ are also the important processes identified by the initial discriminant function, $D_{1}$. Compared to $D_{1}$, the separation with $D_{3}$ is indeed much better with only two overlapping scores. However, while the percentage of discriminable variance was 97 percent with $D_{1}$, it is only 89 percent with $D_{2}$.

\section{Conclusion}

Discriminant function analysis appears quite promising for the empirical analysis of regional economic development. First, it is operationally us eful in classifying the development level of each a rea. Second, the approach has the advantage of identifying processes whichare highly related to regional development. Third, it would appear that the approach has promise in predicting development potential over the short run. The application of the approach to Florida counties has been particularly successful since the discriminant analysis accounted for the particular institutional circumstances of the very diverse Florida economy. 
A brief description of the 21 variables that are used in the discriminant analysis is given below.

\section{Demographic Characteristics}

1. Education level (1960). The median years of formal education for all persons over 25. Source: Office of Economic Opportunity, Community Profile.

2. Percent Non-white (1960). The number of non-whites in each county as a percentage of the county's population. Source: Census of Population, 1960 .

3. Percent over 65 (1960). The number of residents of a county over age 65 as a percentage of the county's population. Source: Census of Population, 1960.

\section{$\underline{\text { Regional Economic }}$ Structure}

4. Non-agricultural Employment (1963). The number of residents of a county employed primarily in non-agricultural pursuits as a percentage of the county's total employment. Source: Researchand Statistics Department, Florida Industrial Commission: Basic Labor Market Information.

5. Manufacturing Employment (1963). The number of residents of a county employed primarily in manufacturing activities as a percentage of the county's total employment. Source: Basic Labor Market Information.

6. Government Employment (1963). The number of residents of a county employed by Federal, State, County, and local governmental units (excluding military personnel) expressed as a percentage of the county's total employment. Source: Basic Labor Market Information.

7. Wages and Salaries Component (1963). Net wages and salaries as a percent of total income for the county. Source: Estimates from the Bureau of Economic and Business Research, University of Florida; published in the Florida Statistical Abstract 1968.

8. Transfer Payments Component (1963). Transfer payments given as a percent of total income for a county. Transfer payments are those payments for which no current productive efforts are given, such as retirement pensions. Source: Florida Statistical Abstract 1968.

9. Labor Force Participation Rate (1963). The number of people in the civilian labor force divided by working age population. Source: Basic $\underline{\text { Labor }}$ Market Information and Florida Statistical Abstract.

\section{Location Factors}

10. Income in Contiguous Counties (1963). Average income per worker in all contingent counties. Income per worker determined from county wages adn aslaries divided by county employment.

11. Transportation Adequacy (1963). A weighted index was developed that consideredfourforms of transportation: railroads, non-interstate roads, interstate freeways, and scheduled airtransportation. Source: Budget of the Highway Commission. 
12. Size of County (1963). Total county population. Source: Florida Statistical Abstract.

13. Index of Natural Amenities (1963). Each county was given a rating of 0-10 on each of four amenity characteristics: (1) average high, February air temperature; (2) miles of usable beach with more than 40 feet of width; (3) number of fresh water lakes; and (4) acres of bay frontage. The index is the average of these four amenity characteristics. Source: Unpublished estimates by the Florida Outdoor Recreation Council.

14. Urbanization (1960). The percentage of the county's population living in urban places. An urban place is defined as an incorporated or unincorporated place of over 2,500 inhabitants and the densely populated urban fringe around cities of 50,000 or more. Source: Census of Population.

\section{Miscella neous}

15. Loan-to-Deposit Ratio (1963). The total loans outstanding for the banks in a county is divided by the total deposits in those banks. Source: Supplement to the Statistical Abstract of Florida.

16. Government Outlays Per Capita (1966). Total Federal government expenditures percapita by county. Source: Government Outlays Per Capita 1966.

17. Index of Agricultural Productivity (1966). A weighted index developed from three indicators that experts suggested would be good indicators of agricultural productivity. An average of the standardized values for the following indicators was used: (1) percentage farm operators with high school education or more; (2) percentage of farms classified as Class I or II; and (3) percentage of farms with tractors. Source: Census of Agriculture.

\section{Measures of Regional Development}

18. Per Capita Income (1963). Includes income from all sources received by residents of a county. Source. Florida Statistical Abstract.

19. Income Received per Worker (1963). All personal income received by residents of a county less all transfer payments, divided by the county's employment. Source: Florida Statistical Abstract and Basic Labor Market Information.

20. Level of Employment. The average level of unemployment for the county between 1960 and 1966. Source: Basic Labor Market Information.

21. Level of Poverty (1963). The percentage of families in a county receiving incomes below the Social Security Administration poverty cutoff level in 1963. Source: Office of Economic Opportunity, Community Profile. 
TABLE I - PRELIMINARY COUNTY CLASSIFICATION

(Based on Development Level)

\begin{tabular}{llll} 
High & Medium & Low & Unclassified \\
\cline { 2 - 4 } Brevard & Alachua & Baker & Charlotte \\
Collier & Bay & Bradford & Flagler \\
Duval & Broward & Calhoun & Gulf \\
Escambia & Columbia & Citrus & Polk \\
Glades & DeSoto & Clay & \\
Hendry & Hardee & Dixie & \\
Highland & Hernando & Franklin & \\
Hillsborough & Manatee & Gadsen & \\
Indian River & Marion & Gilchrist & \\
Lake & Nassau & Hamilton & \\
Lee & Putnam & Holmes & \\
Leon & St. Johns & Jackson & \\
Martin & St. Lucie & Jefferson & \\
Monroe & Santa Rosa & Lafayette & \\
Okaloosa & Taylor & Levy & \\
Orange & Volusia & Liberty & \\
Palm Beach & & Madison & \\
Pinellas & & Okeechobee & \\
Sarasota & & Osceola & \\
& & Pasco & \\
& & Seminole & \\
& & Sumter & \\
& & Suwannee & \\
& & Union & \\
& & Wakulla & \\
& & Walton & \\
& & Washington &
\end{tabular}




\section{Income Per Capita}

Level of Unemployment

Level of Poverty

Earned Income Per Worker

Education Level

Percent Non-White

Percent Over 65

Non-Agricultural Employment

Manufacturing Employment

Government Employment

Wages and Salaries Income

Transfer Payments

Labor Force Participation Rate

Income in Contiguous Counties

Transportation Adequacy

Size of County

Natural Amenities

Urbanization

Loan-to-Deposit Ratio

Government Outlays Per Capita

Agricultural Productivity

\begin{tabular}{|c|c|c|c|c|c|}
\hline 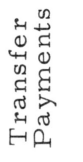 & 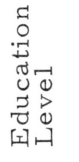 & 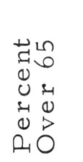 & 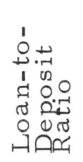 & $\begin{array}{l}\mathscr{1} \\
A_{1} \\
H_{1} \\
\mapsto\end{array}$ & 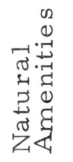 \\
\hline .42 & .12 & .11 & -.16 & .52 & $\because 26$ \\
\hline .24 & -.11 & .00 & .09 & -.14 & .11 \\
\hline .02 & .25 & -.41 & -.16 & .08 & -.29 \\
\hline-.48 & .15 & -.35 & .04 & -.48 & -.04 \\
\hline .25 & 1.00 & .48 & .29 & -.28 & .29 \\
\hline .06 & -.22 & -.03 & -.12 & -.12 & -.06 \\
\hline .56 & .48 & 1.00 & .16 & .02 & .49 \\
\hline .13 & .34 & .06 & .21 & -.26 & -.06 \\
\hline-.15 & -.16 & -.15 & .15 & .10 & -.23 \\
\hline-.11 & .10 & -.34 & .20 & -.22 & -.38 \\
\hline-.20 & .06 & -.50 & .15 & -.22 & -.34 \\
\hline 1.00 & .25 & .56 & .27 & -.22 & .16 \\
\hline-.22 & -.28 & .02 & -.24 & 1.00 & .05 \\
\hline-.10 & -.19 & -.19 & -.01 & .18 & -.23 \\
\hline .11 & .05 & .00 & .15 & .10 & -.09 \\
\hline .00 & .23 & .17 & .09 & .16 & .26 \\
\hline .16 & .29 & .49 & -.15 & .05 & 1.00 \\
\hline .19 & .42 & .44 & .20 & .11 & .27 \\
\hline .27 & .29 & .16 & 1.00 & -.24 & -.15 \\
\hline-.22 & .35 & -.12 & .12 & -.15 & -.18 \\
\hline-.07 & .10 & .31 & -.09 & .06 & .42 \\
\hline
\end{tabular}

TABLE III - MEANS OF VARIABLES IN DISCRIMINANT FUNCTION (D 1 ) *

\begin{tabular}{|c|c|c|c|}
\hline Percent Transfer Payment & $\frac{\text { High Group }}{-.806}$ & $\frac{\text { Medium Group }}{-.228}$ & $\frac{\text { Low Group }}{.765}$ \\
\hline Education Level & .831 & .219 & -.778 \\
\hline Loan-to-Deposit Ratio & .387 & .473 & -.859 \\
\hline Labor Force Participation Rate & .667 & .152 & -.669 \\
\hline Natural Amenities & .626 & .101 & -.550 \\
\hline
\end{tabular}

* All variables are measured in their standardized form. 


\section{TABLE IV - GROUP MEMBERSHIP PROBABILITIES OF INDIVIDUAL COUNTIES \\ (Using Discriminant Function $D_{1}$ )}

Probability of Membership in Group

County Discriminant Score High Medium Low

Original Classification High

\begin{tabular}{|c|c|c|c|c|}
\hline \\
\hline Brevard & 7.03 & .96 & .04 & .00 \\
\hline Collier & 2.16 & .83 & .17 & .00 \\
\hline Duval & 1.65 & .71 & .29 & .00 \\
\hline Escambia & 1.80 & .61 & .39 & .00 \\
\hline Glades & -.34 & .53 & .35 & .12 \\
\hline Hendry & 3.82 & .94 & .06 & .00 \\
\hline Highland & -1.28 & .14 & .83 & .03 \\
\hline Hillsborough & 1.71 & .70 & .30 & .00 \\
\hline Indian River & .93 & .58 & .42 & .00 \\
\hline Lake & .16 & .48 & .51 & .01 \\
\hline Lee & 2.33 & .81 & .19 & .00 \\
\hline Leon & 3.02 & .91 & .09 & .00 \\
\hline Martin & $\cdot 1.05$ & .69 & .31 & .00 \\
\hline Monroe & 1.49 & .63 & .37 & .00 \\
\hline Okaloosa & 1.27 & .70 & .30 & .00 \\
\hline Orange & 2.71 & .83 & .17 & .00 \\
\hline Palm Beach & 5.51 & .99 & .01 & .00 \\
\hline Pinellas & .12 & .47 & .52 & .01 \\
\hline Sarasota & .94 & .64 & .35 & .01 \\
\hline \multicolumn{5}{|c|}{ Original Classification Medium } \\
\hline Alachua & 2.30 & .76 & .24 & .00 \\
\hline Bay & .99 & .60 & .40 & .00 \\
\hline Broward & 2.26 & .83 & .17 & .00 \\
\hline Columbia & -2.64 & .05 & .85 & .10 \\
\hline Desoto & -2.62 & .07 & .57 & .36 \\
\hline Hardee & -2.09 & .09 & .80 & .11 \\
\hline Hernando & -3.51 & .02 & .71 & .27 \\
\hline Manatee & -2.88 & .05 & .67 & .28 \\
\hline Marion & -1.52 & .37 & .63 & .00 \\
\hline Nassau & -1.36 & .18 & .76 & .06 \\
\hline Putnam & -1.23 & .23 & .68 & .09 \\
\hline St. Johns & .27 & .53 & .46 & .01 \\
\hline St. Lucie & -.36 & .36 & .61 & .03 \\
\hline Santa Rosa & -2.82 & .04 & .68 & .28 \\
\hline Taylor & -2.37 & .08 & .75 & .17 \\
\hline Volusia & 1.88 & .72 & .28 & .00 \\
\hline \multicolumn{5}{|c|}{ Original Classification Low } \\
\hline Baker & -6.52 & .00 & .03 & .97 \\
\hline Bardford & -4.41 & .01 & .37 & .62 \\
\hline Calhoun & -5.52 & .00 & .04 & .96 \\
\hline Citrus & -4.31 & .00 & .02 & .98 \\
\hline Clay & -3.05 & .03 & .28 & .69 \\
\hline Dixie & -4.12 & .01 & .27 & .72 \\
\hline Franklin & -3.75 & .01 & .16 & .83 \\
\hline Gadsden & -3.89 & .01 & .42 & .57 \\
\hline Gilchrist & -5.18 & .00 & .01 & .99 \\
\hline Hamilton & -6.43 & .00 & .05 & .95 \\
\hline Holmes & -9.57 & .00 & .00 & 1.00 \\
\hline Jackson & -3.94 & .01 & .40 & .59 \\
\hline Jefferson & -5.93 & .00 & .01 & .99 \\
\hline Lafayette & -4.64 & .00 & .05 & .95 \\
\hline Levy & -5.24 & .00 & .01 & .99 \\
\hline
\end{tabular}


TABLE IV (continued)

Probability of Membership in Group

\begin{tabular}{|c|c|c|c|c|}
\hline County & Discriminant & Score & Medium & Low \\
\hline \multicolumn{5}{|c|}{ Original Classification Low } \\
\hline Liberty & -5.93 & .00 & .00 & 1.00 \\
\hline Madison & -5.24 & .00 & .03 & .97 \\
\hline Okeechobee & -.96 & .32 & .57 & .11 \\
\hline Osceola & -4.22 & .00 & .12 & .88 \\
\hline Pasco & -6.31 & .00 & .06 & .94 \\
\hline Seminole & -.51 & .30 & .68 & .02 \\
\hline Sumter & -6.64 & .00 & .00 & 1.00 \\
\hline Suwannee & -4.13 & .01 & .57 & .42 \\
\hline Union & -6.65 & .00 & .04 & .96 \\
\hline Wakulla & -7.87 & .00 & .00 & 1.00 \\
\hline Walton & -6.60 & .00 & .00 & 1.00 \\
\hline Washington & -7.36 & .00 & .00 & 1.00 \\
\hline \multicolumn{5}{|c|}{ Originally Unclassified } \\
\hline Charlotte & -3.51 & .00 & .07 & .93 \\
\hline Dade & 4.83 & .90 & .10 & .00 \\
\hline Flagler & -1.74 & .29 & .70 & .01 \\
\hline Gulf & .99 & .71 & .27 & .02 \\
\hline Polk & .78 & .51 & .42 & .01 \\
\hline
\end{tabular}


* The research assistance of David Thompson and the advice of Dr. William E. Laird are greatly appreciated. The F.S. U. Computing Center, partially supported by NSF Grant GJ367, provided indispensible services.

I Irma Adelman and Cynthia Taft Morris, "Performance Criteria for Evaluating Economic Development: An Operational Approach," Quarterly Journal of Economics, May 1968, LXXXII, pp. 260-80.

${ }^{2}$ Ibid., p. 260.

${ }^{3}$ Reaction to the blatant empiricism inherent in the discriminant analysis approach used by Adelman-Morris has been strong. The dialogue between Adelman-Morris and Peter Eckstein is revealing. (See Peter Eckstein, "An Econometric Model of Development: Comment," American Economic Review, March 1970, LX, pp. 227-35, and Irma Adelman and Cynthia Taft Morris, "An Econometric Model of Development: Reply, "pp. 236-48 of the same issue.) On methodology, Eckstein's basic objection is the lack of theory used by Adelman-Morris in applying discriminant analysis to underdeveloped nations, i.e., their heavy dependence upon the inductive method, to the near exclusion of deductive elements. While the history of science indicates that progress has tended to take place when the deductive and the inductive are blended together, that same histöry does not suggest that the purêly deductive or the purely inductive will not be fruitful lines of inquiry in any given instance. Eckstein states, "...but completely unstructured techniques, in which theory and prior knowledge are neither tested nor used to order the relationships are the least likely to produce meaningful results." (p. 234.) Still, they might. Indeed, Adelman-Morris argue that the more inductive approach is called for in analyzing underdeveloped nations because of the failure of the more theoretical, deductive approach.

${ }^{4}$ For an excellent description of procedure see William W. Cooley and Paul R. Lohnes, Multivariate Procedures for the Behaviorial Sciences, (John Wiley \& Sons, Inc., 1962), Chapters 6 and 7. For comparison of discriminant analysis utilizing two groups and linear probability (regression) functions, see George W. Ladd, "Linear Probability Functions and Discriminant Functions, "Econometrica, October 1966, XXIV, pp. 873-85.

${ }^{5}$ The weaker standard applied to unemployment as compared to poverty reflects ourbelief that the estimation of county unemployment is inherently more unreliable.

${ }^{6}$ Note that some of the variables, such as the index of natural amenities are weighted composites of several other variables. The weights used were a matter of judgement. We did do some experimentation with alternate weighting schemes and found that the results were not too sensitive to these changes.

${ }^{7}$ All variables are in standardized form, an expediency which facilitates visual comparison.

${ }^{8}$ Retirement income, as part of transfer payments, does not include private pension payments. Nevertheless, the two are probably very highly correlated. Social security payments and government pensions are a large component of all retirement income. Also, areas with large social security payments are also likely to be areas with large private pension payments.

${ }^{9}$ Cooley and Lohnes, op. cit., p. 138. 